\title{
A produção didática da história nos manuais para professores
}

\author{
André Luiz Paulilo \\ Universidade Estadual de Campinas
}

\section{Resumo}

Este artigo expõe resultados de pesquisa acerca do ensino de história. Tratase da análise dos manuais do professor das 19 coleções de livros didáticos de história recomendados pelo Plano Nacional do Livro Didático de 2008 (PNLD2008). 0 estudo busca mostrar os manuais do professor como fonte de pesquisa. A discussão fundamenta-se na ideia de que os manuais do professor trazem representações acerca do ensino. Ao traçar um breve inventário das práticas de ensino nos manuais didáticos, reflete-se sobre as concepções de ensino de história no material ali divulgado. Conclui-se que essas concepções permitem evidenciar algumas das mais importantes características da prática dos professores.

Palavras-chave: Ensino de história. Manuais do professor. Ensino fundamental. Práticas de ensino. 


\section{The didactic production of History in teachers' manuals}

This article presents research findings on the teaching of history, centered on the results of the analysis of teachers' manuals from 19 collections of history textbooks recommended by PNLD-2008. The study approaches teachers' manuals as a research resource. The discussion is based on the idea that teachers' manuals contain representations of teaching. By briefly outlining the teaching practices in the teachers' manuals, the author reflects on the conceptions of the teaching of history in the material studied. The conclusion is that these conceptions reveal some of the most important characteristics of teachers' practices.

Keywords: Teaching of History. Teachers' Manuals. Elementary Education. Teaching Practices.

\section{La producción didáctica de la historia en los manuales para profesores}

Este artículo presenta los resultados de una encuesta sobre la enseñanza de la historia. Estos son los resultados de los análisis de los manuales del maestro de 19 colecciones de libros de texto de historia recomendado por el Plan Nacional del Libro Didáctico(PNLD-2008). El estudio pretende mostrar los manuales del profesor como recurso de investigación. El debate se basó en la idea de que los manuales del profesor traer representaciones acerca de la enseñanza. Al esbozar un breve inventario de las prácticas de enseñanza en los libros de texto, el autor reflexiona sobre los conceptos de la enseñanza de la historia en el material publicado. En conclusión, se trata de ver cómo estos conceptos permiten poner de relieve algunas de las características más importantes de la práctica docente.

Palabras clave: Enseñanza de la historia. Guías para los maestros. Educación básica. Prácticas educativas 


\section{Introdução}

Atualmente, o manual que acompanha o exemplar do professor dos livros didáticos propõe referenciais e preocupações sobre o como, o que e por que ensinar, cujo estudo permite amealhar pressupostos teóricos e elementos metodológicos constitutivos de uma disciplina escolar. Trata-se de um artifício editorial que, diante das necessidades da sala de aula e das demandas postas pelo Programa Nacional do Livro Didático (PNLD), adquiriu relevância como instrumento de orientação e atualização do professor. A atenção a este fato, na análise dos manuais do professor das 19 coleções de livros recomendados pelo PNLD-2008 na área de história, apontou um conjunto específico de aspirações práticas, de regras didáticas e de pressupostos teóricos que julguei merecer análise sistematizadora. Não só porque o manual do professor mantém relação com um sistema construído consoante categorias, esquemas de percepção e de apreciação, regras acerca do que e como deve ser ensinado, mas também porque é visto aqui como fonte de pesquisa a respeito das formas como se vêm aplicando, para fins didáticos, os atuais paradigmas organizadores do discurso sobre as práticas de ensino. Sobretudo, as condições de produção dos manuais do professor remetem para a maneira como esses paradigmas se criam e estabelecem.

Nesse sentido, a lógica que se escolheu para legitimar uma escolarização e as práticas sobre as quais se encontra fixada constituem a problemática da análise. Tratase de um inventário das tarefas associadas ao exercício da docência, dos expedientes utilizados para conduzir as aprendizagens e dos materiais referenciados nos manuais do professor das 19 coleções didáticas de história recomendadas pelo PNLD-2008¹. 0 estudo desse levantamento cingiu-se ao cotejo com as rotinas de trabalho sugeridas e que se solicita ao professor realizar. Principalmente por essa razão, discute-se o manual do professor apenas como peça de prescrição metodológica e controle técnico da prática de ensino. Embora o acumulado das análises já tenha avançado em importantes questões de pesquisa e compreendido o livro didático como um produto cultural dotado de grande complexidade, ainda é pouco o que se tem escrito sobre os manuais do professor que o acompanham. A abordagem e a caracterização do chamado livro do professor, que anexo ao livro do aluno traz o manual do professor, é hoje principalmente feita pelos avaliadores do PNLD. Trata-se de um critério de julgamento e qualificação da coleção didática. Como parte dos quesitos que o edital de seleção das obras didáticas considera obrigatórios, a avaliação do manual do professor está prevista no processo de aquisição de livros pelo PNLD desde há duas décadas. Não obstante seu caráter de resenha, os Guias dos livros didáticos do PNLD

1. Confira lista dos livros analisados ao final do artigo. 
publicados pelo Fundo Nacional de Desenvolvimento da Educação (FNDE) constituem um primeiro referencial de análise desse instrumento de auxílio da prática docente. Um levantamento do que foi feito nesse campo de preocupação pouco avança além dos próprios Guias². Isso mostra, no mínimo, que a compreensão do manual do professor, como dispositivo de auxílio da prática docente e instrumento de formação e atualização do professor, não conta com o amplo conjunto de perspectivas de análise já abertas pelos estudos sobre o livro do aluno. As relações entre produção e consumo, a história, a linguagem e as matizes e clivagens da edição, dos conteúdos e das ideologias também são questões pertinentes à discussão da forma, do referencial teórico e do conteúdo pedagógico do livro do professor.

Ocorre que há questões específicas de análise. 0 manual do professor traz representações da prática de ensino. Com frequência, os discursos que prescrevem, criticam ou excluem, exortando a "boa" prática, têm por origem tanto uma concepção das práticas ilegítimas quanto um referente dos bons métodos, dos bons gestos, das boas leituras. Eles se articulam com as demandas previstas nos editais do PNLD, com as trajetórias profissionais de seus autores e com as estratégias editoriais de publicação dos livros didáticos no país. Desse modo, os manuais do professor correspondem à fidelidade sempre regulada das opções autorais e são comandados pelo projeto que conduz a coleção. Nesses textos, o ensino e as demais ações docentes aparecem como representação. Principalmente as prescrições do livro do professor partilham as questões e as expectativas das utilizações metodológicas, sobretudo, organizando-se com base em representações sobre os gestos do ensino. Da análise dessas especificidades podem-se extrair elementos que esclarecem parte do conjunto dos discursos sobre as práticas educativas, acerca das prioridades didáticas dos atuais métodos de ensino e a respeito do próprio magistério.

Interrogando-me sobre os modos por meio dos quais o manual do professor promulga e justifica determinadas intenções básicas do ensino de história e as práticas de escolarização ali consideradas importantes e significativas, procura-se sistematizar as rotinas de trabalho sugeridas e que se solicita realizar nesse gênero de texto. Dessa perspectiva, discute-se o manual do professor como peça de prescrição de certezas metodológicas e controle técnico da prática de ensino. São resultados do projeto de pesquisa Perspectivas da História Ensinada, que objetivou entender a produção didática da história por meio da análise do discurso veiculado pelos volumes didáticos do ensino fundamental recomendados para o período 2008-20103. 0 intuito

2. Há, entretanto, membros das comissões de avaliação do Programa Nacional do Livro Didático que começam a publicar suas reflexões sobre esse processo e, assim, têm subsidiado a compreensão do perfil das coleções didáticas recomendadas. Esse é o caso dos estudos de Luca $(2004 ; 2006)$ e de Oliveira (2009).

3. O projeto foi financiado pelo CNPq, na linha Jovens Pesquisadores. Cf. Processo n 563.733/2008-0. 
de fazer desse tipo de impresso uma pista para a investigação sobre o como se pensa a prática do ensino de história fundamentalmente resultou da constatação de Roger Chartier $(1990 ; 1991 ; 2002)$ de que as operações de sentido sobre o mundo social não podem ser dissociadas das condições e dos meios materiais que os fazem circular. Especialmente interessada nos indicadores e nos efeitos da demanda social junto aos professores, a pesquisa investigou as representações acerca do docente de história das séries finais do ensino fundamental em relação ao ensino da sua disciplina.

\section{Das ideias sobre a docência aos produtos para o docente}

Desde que um intenso investimento historiográfico pôs em causa as dimensões retórica e narrativa da história, as análises de Roger Chartier (1990, p. 63) têm insistido que "nenhum texto mantém uma relação transparente com a realidade que apreende". Suas contribuições nessa discussão fundamentalmente mostram que o real não é apenas a realidade visada pelo texto, "mas a própria maneira como ele a cria, na historicidade da sua produção e na intencionalidade da sua escrita". Como resultado de um empreendimento de pesquisa orientado por essa perspectiva sobre os objetos culturais, Chartier afirma que, para se compreenderem as práticas de leitura e de utilização e consumo de impressos, não basta uma abordagem precisa dos dispositivos puramente textuais, resultantes da escrita e da vontade do autor. Também os dispositivos efetivados pelas formas tipográficas são determinantes para a apropriação de um texto. Assim, por um lado, Chartier (2009, p. 40) sempre lembra seu leitor que "a produção não só dos livros, mas também dos próprios textos é um processo que implica, além do gesto da escritura, diferentes momentos, diferentes técnicas e diferentes intervenções", e, por outro, adverte que:

(...) as apropriações concretas e as invenções dos leitores dependem, em seu conjunto, dos efeitos de sentido para os quais apontam as próprias obras, dos usos e significados impostos pelas formas de sua publicação e circulação e das concorrências e expectativas que regem a relação que cada comunidade mantém com a cultura escrita. (Chartier, 2009, p. 43).

As concepções do autor a respeito das práticas culturais que envolvem o texto ao leitor mostram-se, sobretudo, úteis para o entendimento das condições que fazem os manuais dos professores apresentarem a forma, o conteúdo e o valor que têm. Mais que isso, elas sugerem estratégias de análise dos processos da sua elaboração e das regras de escrita próprias desse gênero de texto. Foi este último 
aspecto que se procurei desenvolver neste trabalho. Foi principalmente no veio do trabalho desenvolvido por Anne-Marie Chartier que abordei os manuais do professor das coleções didáticas recomendadas pelo PNLD-2008 como meio de compreender o fazer ordinário das aulas de história. No entanto, diferentemente do programa de pesquisa de Anne-Marie Chartier (2000), renunciei ao inventário dos trabalhos sobre a escola para tratar dos manuais por entender que importa observar nesse tipo de produção as referências que fazem sobre os professores a que se destinam, a fim de perceber como o trabalho docente em história tem sido compreendido. 0 inventário dos enunciados dirigidos ao docente nos manuais do professor dos livros didáticos de história viabilizou uma abordagem das representações do ensino de história produzidas pela edição desses textos.

Em favor dessa perspectiva, preteri outros tipos de análise que a pesquisa sobre a profissão docente e a sua formação consolidou acerca da docência. Assim, não associei a análise desse gênero de texto às práticas etnográficas para estudar os usos dos manuais. 0 esforço foi mais de compreensão das representações do trabalho docente que das relações entre teoria e prática, problemática de estudo e tema já tradicional na literatura pedagógica (cf. Saviani, 1984; André 2005; Carvalho, 2011). Busquei um critério capaz de circunscrever as fontes sem que se precisasse construir uma amostragem estatística baseada em levantamentos que restringissem a análise qualitativa a um conjunto muito específico de dados sobre a formação docente, como o fizeram recentemente com sólidos resultados Bernadetti Gatti e Maria Muniz Rosa Nunes (2008), por exemplo. Os manuais constituem um recorte orientado de acordo com o processo de avaliação do PNLD na área de história, de modo que reúnem a totalidade dos livros didáticos aprovados para o período 20082010. Trata-se de uma perspectiva a qual não se ajustam os estudos de caso e os recursos da história de vida. Não se trata de evidenciar o peso da história de vida pessoal e das experiências de aluno no desempenho docente. Em vez das estratégias de configuração da identidade ou das práticas docentes que as pesquisas de Maria Isabel da Cunha (1989) e Belmira Bueno, Denice Catani e Cynthia Pereira (2002), por exemplo, mostraram ser determinantes da especificidade da experiência docente dos professores, foi o discurso sobre as práticas da sala de aula que motivou esta pesquisa. Enfim, este estudo dos manuais não se pretende teórico. Ao contrário, importou-lhe compreender algo das ideias a respeito da formação e da prática docente que o PNLD consolida a partir da análise dos manuais do professor que nele se recomenda. 0 seu foco está no levantamento das tarefas prescritas nesse gênero de texto, e não na discussão sobre a docência que a defesa da prática reflexiva (cf. Zeichner, 1993; Alarcão, 2003; Pimenta; Ghedin, 2005), ou o esforço para dar um novo estatuto aos saberes da experiência (Tardiff, 2002), especificamente, amparam. 
Portanto, diferentemente dessas perspectivas de pesquisa e não obstante os avanços que têm promovido no modo de entender a formação de professores, debruceime sobre um produto destinado ao ensino e ao docente. A análise questiona mais um instrumento de atualização docente que as ideias acerca da docência e dos professores. Também nesse aspecto, o campo de pesquisa já foi razoavelmente desbravado. Michel Apple (1995, p. 97), por exemplo, adverte da necessidade de "desvendar a lógica de um conjunto bastante complexo de inter-relações". É pertinente o repertório de questões proposto pelo autor:

De que forma a própria economia política da indústria editorial gera necessidades econômicas e ideológicas específicas?

Como e por que os editores respondem às necessidades do "público"?

Quem determina quem constitui o "público"?

Como funciona a política interna do procedimento de adoção de textos escolares?

Como os livros são vendidos no nível local?

Qual é o processo real de produção do texto, desde a encomenda de um projeto, as revisões e processo editorial até a fase de publicidade e vendas? Como e por que razões as decisões são feitas nesse sentido? (Apple, 1995, p. 97).

O que a produção no campo da pesquisa em ensino de história tem acumulado mais recentemente mostra a impossibilidade de qualificar os objetos ou as práticas de ensino nos termos de suas finalidades e metodologias. Daí as novas perspectivas abertas para pensar outros modos de articulação entre as obras ou as práticas didáticas e o mundo social dos sujeitos, alunos ou professores. Nessa direção, Kazumi Munakata (2007) e Elison Paim (2007) apontam caminhos ao se aperceberem do sentido de "cerceamento da autonomia" e de "pseudoparticipação" nas solicitações feitas aos professores de história nos livros didáticos e nas propostas curriculares. As práticas visadas sob essa perspectiva de análise não se confundem com a vivência em sala de aula, com as instituições do ensino de história ou com as relações de dominação e controle do trabalho docente. Pelo contrário, pertencem ao domínio específico das práticas discursivas, bem definido por Foucault (1979) quando propõe considerar os discursos como práticas que obedecem a regras de formação e de funcionamento.

\section{0 manual do professor como fonte de pesquisa}

O que então se questiona é aquilo que os manuais do professor significam e constroem em relação ao regime de práticas observadas no ensino de história. Enfatiza-se que 
é próprio do seu gênero de discurso tratar das estratégias de organização e método do ensino da matéria. Isso não significa dizer que ele efetivamente organiza e institui uma metodologia de ensino, mas que é um indício das condições de sua emergência, inserção e funcionamento. Nessa direção, sobretudo, percebe-se que a ênfase nas práticas de sala de aula é hoje uma postura firmemente sustentada no manual do professor das coleções didáticas de história recomendadas pelo PNLD 20084. As sugestões de atividades e a indicação das técnicas para a condução da aprendizagem compõem no livro do professor um variado repertório de meios e procedimentos de ensino. Trata-se de recursos de apoio ao uso do livro didático, mas também de orientação visando possibilitar o desenvolvimento de estratégias de aula variadas. Assim, a oferta de ajuda dos manuais do professor abre perspectivas para o estudo das orientações sobre as condições, as finalidades e os objetivos do ensino de história. As rotinas de trabalho, os modelos de exercício, os recursos indicados, os roteiros de procedimentos, as práticas de organização da aula e, sobretudo, as orientações visando à articulação de conteúdos e estratégias são elementos com que se podem pensar, não os fundamentos da aprendizagem histórica, como solicitam Bergmann (1989) e Rüsen (1987; 2002), ou os grupos e estruturas que operam e formulam o currículo, ao modo de Goodson (1988; 1995), mas os esquemas de percepção e de apreciação constitutivos do que se entende ser o trabalho do professor de história.

0 manual do professor foi entendido, neste estudo, tanto como um compêndio de especificações técnicas quanto como uma forma de mostrar ao docente que há outras fontes de material didático. Em razão desse seu caráter operacional, mais afeito ao uso no dia a dia do que para ser lido, dá acesso a um discurso sobre a prática de sala de aula, ou seja, ao discurso a respeito do que o professor deve e pode fazer em sala de aula. Entretanto, a abordagem desse tipo de interpelação não é menos útil ao entendimento das expectativas, exigências e necessidades do ensino de história que o trabalho de campo junto aos professores. Sua relevância, porém, tem mais a ver com o estudo de formas específicas de articulação de um gênero de discurso, enquanto as pesquisas empíricas dos procedimentos didáticos do magistério têm considerado os resultados de certas performances e a compreensão do exercício docente por parte do próprio professor (ver Ciampi et al, 1986). Principalmente, a atenção para as instruções operacionais dos suplementos pedagógicos proporciona um contato estreito com normas tácitas da ação em sala. Em conformidade com o que sublinha Anne-Marie Chartier (2007, p. 74 e 149), os subsídios oferecidos pelos manuais do

4. Atualmente a avaliação dos livros didáticos de História que resulta na recomendação do PNLD é feita por uma comissão de especialistas, formadas por pesquisadores da área de história e do ensino de história. Para maiores informações consulte www.fnde.gov.br. 
professor para definir objetivos e programas do ensino é tão marcada pela "cultura de pesquisa do autor, seus valores pedagógicos e políticos, suas preferências culturais e estéticas, sua experiência com crianças e com a aprendizagem escolar", quanto pelo que ele não acredita ser necessário recusar ou criticar, ou mesmo sequer dizer. $E$, nesse sentido, entre a margem de iniciativa em que o professor cria sua maneira de dar aula e os dispositivos pedagógicos de trabalho e orientação da sua prática, há ações das quais pouco se fala.

A parte específica dos manuais do professor, aquela que orienta o uso do livro didático de uma determinada série, são principalmente roteiros de atividades sugestivos numa perspectiva desse tipo. Depois das considerações sobre a fundamentação teórico-metodológica da coleção, seguem as instruções que concernem à realização dos exercícios, das rotinas de trabalho e, por vezes, da própria aula em cada novo ponto da matéria. No sentido de caracterizar as principais configurações desses conjuntos de propostas, procedeu-se de modo a indicar possíveis articulações 5 . A classificação foi organizada por setores, por procedimentos de ensino tratados nos manuais do professor das coleções didáticas recomendadas no PNLD-2008, observando-se ordens de serviço, estratégias de aula, modelos de atividade ou insumos para o trabalho. Importou fazer do levantamento das tarefas associadas ao exercício da docência, dos expedientes utilizados para conduzir as aprendizagens e dos materiais referenciados um meio de lidar com as soluções didáticas elaboradas para operar com os sentidos do ensino da história. Mesmo que de maneira ainda um tanto preliminar, as indicações que então se pôde fazer a respeito dão conta das experiências educacionais que se pensa que as aulas de história podem proporcionar.

\section{Ordens de serviço e estratégias de aula}

No ponto de partida, há a preocupação acerca dos procedimentos de aula. Trata-se de considerações sobre a preparação da aula, o seu encaminhamento e o retorno dos resultados. Assim, considerei como ordens de serviço as instruções para providenciar material, prestar esclarecimentos, corrigir atividades e preparar roteiros de ensino. Essas solicitações são as mais constantes, lembrando-se que a organização do expediente de sala de aula é parte das tarefas do magistério. Os manuais do professor apontam quando preparar a aula, corrigir as atividades, do mesmo modo

5. Por razões de espaço e para maior clareza dos argumentos, não reproduzo nesta análise as passagens dos textos dos manuais que serviram à comparação e que este texto procura sintetizar. Para maiores informações ver Paulilo (2010). 
que sublinham a necessidade de esclarecer, discutir e explicar determinados pontos da matéria ou dos exercícios. Solicita-se do professor, ainda, o fornecimento de matérias de jornais, fotos, materiais e gravuras, de texto, música e filme, de mapas e livros de literatura para o trabalho dos alunos em classe.

Outra preocupação acentuada nesse tipo de texto diz respeito à performance do professor. Não obstante haver toda uma literatura que associa a performance à construção de instrumentos para estimular, julgar e comparar profissionais em termos de resultados (Ball, 2002, 2005; Lyotard, 1998), nos manuais apenas é possível pensá-la como desempenho em aula. Segundo sugere a leitura dos manuais do professor das coleções didáticas de história, o docente pode utilizar uma série de práticas para predispor os alunos, motivando seu interesse pelos temas. Sobretudo nesse sentido é que o professor deve explorar o material trazido pelos alunos, recorrer aos exemplos concretos e fáceis, ler com expressão para motivar o interesse pelo tema, trabalhar oralmente em aula e evitar que a dinâmica do trabalho polarize os debates e divida a sala. As instruções que se encontram nos manuais do professor pedem aos docentes que problematizem em vez de narrarem, que indiquem relações em forma de questionamento, estimulem e orientem o debate, propondo questões motivadoras ou deixando no ar uma questão para reflexão. Igualmente, salientar, reiterar, sugerir, relacionar com o presente, acompanhar a leitura de texto e as pesquisas, orientar os ensaios de peça e a preparação de trabalhos são aspectos que se associam à maneira de ensinar história recomendada nos manuais do professor das coleções didáticas. Também a utilização da lousa tem sido pensada como recurso para otimizar o desempenho do professor em sala de aula. Em vez de suporte para o texto que serviria para a cópia dos alunos, a lousa é indicada para a sistematização de informações, para listar as conclusões dos alunos, enfim, trata-se de um recurso para tornar coletivo o resultado de pesquisa apresentado pelos alunos.

Há, ainda, um conjunto de procedimentos que se sugere adotar para lecionar história nas séries finais do ensino fundamental. Os manuais do professor reúnem tarefas que os professores devem realizar antes, durante e depois da aula. Antes da aula, insiste-se na preparação: elaborar uma pauta do que deve ser discutido, fazer transparências, assistir ao filme antes dos alunos e editá-lo. Durante a aula propriamente, as recomendações vão desde o levantamento dos conhecimentos prévios do aluno até a verificação das tarefas realizadas. A ênfase, então, recai sobre as estratégias que se pode constituir para ensinar e controlar a aula. Nessa perspectiva, a administração do tempo, a conversa com os alunos, o levantamento do significado de palavras desconhecidas de um texto, a orientação da observação de imagens e de mapas, o incentivo à busca de respostas mais precisas às questões, a reprodução de música e a exibição de filmes são frequentemente lembrados. Depois 
da aula, principalmente, requer-se do professor socializar as respostas dos alunos, corrigi-las, rever, retomar ideias dos alunos, expor os seus trabalhos, recolher e arquivar atividades para, quando for o caso, um uso posterior. A leitura dos manuais do professor das coleções didáticas de história mostra que a aula esperada do professor vai além dos procedimentos adotados na sala. Nesse caso, tanto quanto o que se diz e é feito para ensinar história aos estudantes e gerir a aula, também as providências de bastidores, a preparação e o retorno das atividades fazem parte do repertório de procedimentos costumeiramente recomendados ao professor.

\section{Atividades ordinárias e extraordinárias}

Segue que os manuais do professor das coleções didáticas de história organizam em atividades o trabalho de sala de aula. Oferecem uma aplicação exemplar dos conteúdos do livro do aluno em atividades de produção textual, confecção de material, pesquisa, estudo do meio, leitura e discussão. Para realizar uma descrição mais articulada desse conjunto de instruções, distingui as atividades eventuais das atividades de rotina. Considerei atividades de rotina aquelas que aparecem constantemente indicadas em diversos temas desenvolvidos pela coleção didática e que, portanto, parecem ser cotidianas no ensino de história. Por outro lado, entendi como atividades eventuais aquelas que têm sentido fazer só no caso de compreender um determinado tema, de considerar o entorno social do aluno ou, então, de tratar de questões específicas do passado e da história ainda presentes atualmente e que, por isso, marcam momentos excepcionais de trabalho escolar.

Em muitos sentidos, as atividades rotineiras recomendadas nos manuais do professor das coleções didáticas corroboram os afazeres já há muito praticados na escola. Para a formação intelectual do estudante, por exemplo, definir, comparar, explicar relações de significância, enumerar, comentar, propor questões, sintetizar, lembrar, recapitular e ler individualmente e de forma antecipada os textos continuam sendo expectativas importantes. Também na produção material dos alunos a elaboração de cartazes e de material visual, a coleta de imagens, a montagem de quadros comparativos, as colagens, a consulta a jornais e revistas e o manuseio de objetos permanecem práticas respeitadas e recomendadas. Do mesmo modo, desenhar, encenar, representar ideias, situações ou objetos por meio de diferentes linguagens, confeccionar mapas, construir quadros sinópticos, produzir ou interpretar caricaturas e charges já são práticas incorporadas ao ensino de história nas escolas,

práticas cuja observância ainda se recomenda. Às tradicionais anotações no caderno, práticas variadas de pesquisa, classificações, relatórios, resumos e questionários 
somam-se versões atualizadas do registro escrito: produção de textos, tabulações, indicação gráfica, elaboração de esquetes ou enredos para dramatização. Igualmente, associa-se ao ensino de história a realização de entrevistas, de apresentações orais de diversos tipos, de debates e de descrição oral. Dar opinião e responder a questões motivadoras e problematizadoras completam esse quadro de atividades orais que o ensino de história costumeiramente exige. Com frequência, a qualificação das práticas de leitura tem sido considerada mais uma atribuição do ensino de história. Nesse sentido, alguns dos manuais do professor analisados recomendam com alguma insistência o exercício da leitura em voz alta, a prática da leitura dirigida e da leitura criativa. 0 trabalho a partir de documentos ocupa uma parte importante das recomendações dos manuais e se articula tão bem com as novas exigências e operações da aprendizagem do pensamento lógico e crítico quanto com práticas mais ancestrais do ensino de história, como a elaboração de quadros cronológicos, o trabalho em grupo e a leitura em dupla.

Por outro lado, o conjunto das atividades mais excepcionais que se pôde reunir lendo os manuais do professor indica que o ensino de história também tem sido um espaço para as crianças e adolescentes se mostrarem em suas obras e interagirem. Por meio de entrevistas, jogos e excursões, o aluno vivencia uma concepção de história em que a participação e a tolerância importam tanto quanto os "lugares de memória", isto é, as instituições que nos servem de testemunho de outra época, conforme sugere Nora $(1993)^{6}$. A prática da entrevista com pessoas da comunidade, familiares e professores e a consulta aos mais velhos prestigiam a memória que o outro carrega, legitima uma relação com o passado. Em estudo recente, Kazumi Munakata (2007) observou que há problemas no modo como essas sugestões são feitas. Segundo percebe Munakata (2007, p. 141-143), “no rol das pessoas a ser entrevistadas, há tipos humanos que não são encontráveis em qualquer lugar e meio social", e, mesmo quando encontrados, não são todos que estão dispostos a expor suas experiências e práticas, principalmente se forem dolorosas e passíveis de preconceito. Geralmente sugeridas diretamente aos alunos no livro texto, quando caberia ao professor organizá-las, incitam o aluno a passar por cima da competência e autonomia do professor da disciplina.

Já os jogos de adivinhação, de perguntas e respostas ou de percurso e a reconstituição de jogos de outros tempos e culturas são recomendados para

6. Para Nora (1993, p. 13), “os lugares de memória nascem e vivem do sentimento que não há memória espontânea, que é preciso criar arquivos, que é preciso manter aniversários, pronunciar elogios fúnebres, notariar atas, porque essas operações não são naturais." Segundo o autor, mesmo um lugar de aparência puramente material, como um museu ou um depósito de arquivos, “só é lugar de memória se a imaginação o investe de uma aura simbólica" (Nora, p. 21). 
prender o máximo de sentido histórico num mínimo de sinais e códigos e consolidar solidariedades numa dinâmica de participação francamente lúdica. No ensino de história, as excursões a monumentos e museus são práticas que há tempos se observam como forma de fixar um estado de coisas e materializar um conjunto de significados. Ultimamente, e os manuais de professores indicam-no, a visita ao arquivo da cidade, aos sítios arqueológicos, à câmara municipal, às agências de turismo ou ao supermercado ou mercearia cumpre função semelhante. A percepção de que o ensino de história propicia a oportunidade de o aluno entrar em contato com práticas, produtos, trabalhos e tarefas coletivas também está consolidada nas coleções didáticas da área. Assim, seja na elaboração de um calendário, seja na construção de uma ampulheta ou maquete, seja na confecção de um livro de receitas, os expedientes práticos que se veiculam nos manuais do professor permitem incorporar o fazer dos alunos e seu produzir ao ensino da história. Do mesmo modo, dramatizar uma cena, produzir um fóssil de maneira artificial ou um mosaico, imitar pintura rupestre, organizar um álbum da turma ou um arquivo pessoal de matérias interessantes, criar um prospecto turístico, contribuir na confecção de uma caixa da saudade, montar um arquivo de imagens, confere ao ensino de história uma propensão mais ativa e produtiva.

Outro ponto de contato entre as coleções didáticas de história pôde ser identificado: as estratégias visando à exposição dos resultados obtidos com as atividades. Nos manuais do professor, há um elenco de propostas sobre como conduzir as atividades ordinárias e extraordinárias em sala de aula. Trata-se de abordar os modos considerados adequados de externar os produtos da aprendizagem. As formas consagradas das exposições escolares permanecem uma referência importante. Assim, a apresentação oral, a elaboração de mural, painel ou cartaz e a dramatização teatral continuam tendo importante presença entre as sugestões indicadas nos manuais do professor das coleções didáticas de história. Expor os produtos da aprendizagem é uma preocupação que ratifica o uso de recursos e estratégias didáticas mais ativas no ensino de história. As propostas de musicar, simular um programa de auditório ou um telejornal e filmar seguem a mesma direção, valorizando mais as dimensões consideradas formadoras das atividades programadas na sala de aula ou na escola. Mais uns que outros, os manuais do professor percebem as formas de apresentação e exibição dos trabalhos discentes como registros daquilo que o ensino de história pode manifestar. Principalmente, a exposição dos resultados de pesquisa e dos trabalhos escolares é tida como recurso didático que valoriza os produtos pelos quais os alunos aprenderam a matéria. Nesse sentido, a organização de mostras, de feiras de cultura ou de apresentações dos alunos que os manuais do professor recomendam também reitera práticas usuais da escola e dos docentes 
como a produção coletiva de atividades, a centralidade conferida às práticas e a externalização de produtos.

\section{Os insumos para a aula}

Os manuais dos professores das coleções didáticas reúnem textos e referências que servem de insumo para o trabalho docente. Em muitos sentidos, trata-se de uma compilação de informações complementares e de recursos para a atualização do professor visando estimulá-lo a compreender a leitura e a utilização de fontes presentes em seu local de atuação como parte constitutiva das suas condições de trabalho. Assim, o repertório de autores e obras, de fontes, de meios e de linguagens com os quais lidam os manuais de professores não só informam sobre o ensino da matéria, mas principalmente consolida tendências de socialização dos bens culturais. Por um lado, as citações de textos para apoio do professor e de indicação de filmes, músicas, livros e quadrinhos para trabalho em sala de aula dizem muito sobre a perspectiva que os manuais apresentam para o ensino da história. Há tanto coleções em que predominam as referências aos historiadores de ofício nos seus manuais do professor quanto as que incorporam neles um repertório mais significativo de indicações de romancistas, músicos, cineastas e cartunistas. Insistir na autoridade que autores como Marc Bloch, Le Goff, François Dosse, Eric Hobsbawn ou Perry Anderson têm no campo da história e apoiar neles as referências de leitura indicadas ao professor reforçam a especialização docente e as premissas teóricometodológicas do ofício do historiador. Do mesmo modo, a história problematizada por meio de canções e filmes e por meio da literatura, ou das histórias em quadrinhos, mostra o espaço que há no ensino de história para o trabalho com diferentes manifestações culturais. A presença das canções de Chico Buarque e Renato Russo, dos quadrinhos de René Goscinny e Albert Uderzo, Ziraldo e Miguel Paiva ou de imagens dos Flintstones e de Charles Chaplin propõe considerar no ensino as várias possibilidades da representação da história fora dos ambientes da escola. Conforme uma vez entendeu Klaus Bergmann (1989, p. 35), trata-se de dimensões diferentes de uma única conexão constituída pela indagação acerca de uma maneira particular de pensar que é a história.

Por outro lado, o trabalho sustentado em documentos ocupa uma parte importante das recomendações dos manuais do professor das coleções didáticas de história. Solicita-se que parte da pesquisa escolar ocorra a partir de fontes como, por exemplo, revistas, artigos de jornal, periódicos e mapas locais, fotografia, documentos pessoais, peças publicitárias, legislação e depoimentos orais. Os 
manuais do professor lembram ao docente que diários, cartas, cartões postais, charges, monumentos e moedas também servem como material para um trabalho com fontes documentais. Sobretudo, a constatação de que atualmente se vem insistindo na coleta e manipulação de um material desse tipo sugere a incorporação de procedimentos do fazer da história no ensino. Nesse sentido, aos conteúdos somam-se as aprendizagens das operações intelectuais que permitem a construção de um discurso. Como bem percebeu Dominique Borne (1998, p. 139), também no ensino de história os documentos devem ser cuidadosamente identificados e inscritos numa cronologia e depois postos em relação com outros documentos. Ainda que as preocupações com a aprendizagem das operações de construção do discurso histórico se venham firmando, estão longe de substituir as usuais recomendações acerca da pesquisa escolar em revistas, enciclopédias, dicionários, atlas geográfico, livros, almanaques e, mais recentemente, na internet. 0 uso ilustrativo de imagens, por meio das reproduções de pinturas, gravuras e fotografias e dos folhetos turísticos e histórias em quadrinhos, permanece parte das recomendações de ensino da história. Enfim, o repertório de materiais possíveis de aplicação nas aulas de história que os manuais do professor indicam não só é numeroso e variado, como viabiliza modalidades de transmissão moduladas em função das questões do presente. Entre tudo o que então se indica utilizar para lecionar a história, os manuais do professor das coleções didáticas de história evidenciam as possibilidades de estudo na utilização dos documentos, das mídias e dos impressos escolares como recursos didáticos.

\section{Considerações Finais}

0 manual do professor das coleções didáticas recomendadas pelo PNLD - 2008 veicula considerações sobre a preparação da aula, o seu encaminhamento e o retorno dos resultados, propõe estratégias educativas e modelos de atividade, e oferece insumos que expressam objetivos práticos e utilitários de ensino. Portanto, nesse tipo de impresso se articulam ao conteúdo explícito uma concepção de aprendizagem e um repertório de textos e referências para o trabalho docente. Na área de história, os manuais do professor organizam e sistematizam conteúdos e procedimentos visando não apenas auxiliar a prática do ensino, mas também contribuir para uma formação contínua do docente. Conforme recomenda o edital de convocação para inscrição no processo de avaliação e seleção de obras didáticas do PNLD-2008, trata-se, assim, de um recurso de “orientação teórico-metodológica" (Brasil, 2007, p. 2). Nesse sentido, fundamentalmente os manuais do professor recomendados para a área de história têm veiculado discursos sobre o modo de ensinar a matéria junto aos que 
atuam na prática. 0 estudo desses discursos parece indicar que são insistentemente lembrados aos professores de história os gestos e fazeres já bastante associados à docência. 0 inventário das rotinas de trabalho escolhidas e retrabalhadas nos manuais do professor reitera estratégias de ensino, instrumentos para as aulas e textos para compreender e pensar sem considerar a desenvoltura necessária à condução de uma turma de alunos ou o valor de uso de muitas das "receitas" propostas. Dessa perspectiva, as omissões sobre a complexidade da realização do trabalho educativo por parte dos manuais do professor das coleções didáticas de história são tão representativas do que se solicita que o docente da matéria faça da sua prática quanto o que se propõe e reproduz explicitamente.

Em muitas coleções recomendadas no PNLD-2008, os esclarecimentos sobre os conteúdos da disciplina visam contribuir para se ver com maior clareza o que deve ser ensinado. Do mesmo modo que há expectativas quanto ao que é ensinado, esses impressos expressam a expectativa de que, na maneira de ensinar, o docente de história comente e explique a matéria, relacione os fatos, destaque conteúdos, demonstre os processos de mudança ao longo do tempo, informe sobre a atualidade de algumas questões históricas e estimule a aprendizagem do aluno. Se em alguma medida se pode concluir que a docência em história se caracteriza por fazer intervirem nos atuais assuntos de interesse da juventude explicações racionais e exigências de convivência e participação social, um dado interessante é a exígua presença de orientações relacionais que não as de ordem operacional: orientar, acompanhar, corrigir, estimular, avaliar, explicar, solicitar.

No quadro compreensivo que então se pode propor a respeito das exigências as quais se procura fazer o docente interiorizar, inventariei as estratégias e rotinas tidas como constitutivas da prática do ensino de história pelos manuais do professor. Principalmente, há operações que, sob a justificativa de tornar os utensílios conceituais da história menos opacos ao entendimento dos docentes e alunos, visam atingir o fundo e a forma da narração histórica em sala de aula. Por um lado, predominam orientações para organizar as rotinas de elaboração visual das aprendizagens (cartazes, painéis e construção de materiais), de discussão e reflexão (debates, seminários e entrevistas) ou de síntese (exposições, resumos), e as dinâmicas de jogos e representações. Por outro lado, percebe-se a elaboração de abordagens didáticas cada vez mais capazes de refletir os avanços da ciência histórica e a incorporação de soluções pedagógicas propostas para o ensino de história. Assim, a partir do levantamento, realizado nos manuais didáticos, dos principais tipos de atividades e das técnicas de ensino, a análise focou o conjunto de práticas que se definem por meio dos modos de percepção e de apreciação constitutivos do que se entende ser o trabalho do professor de história. 


\section{Referências Bibliográficas}

ALARCÃO, Isabel. Professores reflexivos em uma escola reflexiva. São Paulo: Cortez, 2003. Coleção questões da nossa época, v. 104.

ANDRÉ, Marli Eliza Dalmazo Afonso de. Etnografia da prática escolar. 12. ed. Campinas: Papirus, 2005.

ANTONACCI, Maria Antonieta; SILVA, Marcos. Vivências da contramão - produção de saber histórico e processo de trabalho na escola de $1^{\circ}$ e $2^{\circ}$ Graus. Revista Brasileira de História. São Paulo, v. 9, n. 19, p. 9-29, set. 89/fev. 90.

APPLE, Michael W. Trabalho docente e textos: economia das relações de classe e de gênero em educação. Porto Alegre: Artes Médicas, 1995.

BALL, Stephen J. Profissionalismo, gerencialismo e performatividade. Cadernos de Pesquisa, São Paulo, v. 35, n. 126, p. 539-564, set./dez. 2005.

- Reformar escolas/reformar professores e os terrores da performatividade. Revista Portuguesa de Educação, Braga, v. 15, n. 2, p. 3-23, 2002.

BERGMANN, Klaus. A história na reflexão didática. Revista Brasileira de História. São Paulo, v. 9, n. 19, p. 29-42, 1989.

BITTENCOURT, Circe. Capitalismo e cidadania nas atuais propostas curriculares de história. In. (org.). O saber histórico na sala de aula. São Paulo: Contexto, 1997, p. 11-27. (Coleção Repensando e Ensino).

BORNE, Dominique. Comunidade de memória e rigor crítico. In: BOUTIER, Jean.; JULIA, Dominique. (Orgs.) Passados recompostos: campos e canteiros da história. Rio de Janeiro: UFRJ/FGV, 1998, p. 133-141.

BRASIL (MEC-FNDE). Edital de convocação para inscrição no processo de avaliação e seleção de obras didáticas a serem incluídas no Guia de Livros Didáticos para os anos finais do ensino fundamental. In: <ftp://ftp.fnde.gov.br/web/editaislicitações/edital_ pnld-2008pdf $>$. Acessoem : 9 jan. 2007.

BRASIL. MEC. Guia de livros didáticos PNLD 2008: História. Brasília: MEC, 2007.

BUENO, Belmira; CATANI, Denice Bárbara; SOUSA, Cynthia Pereira (Orgs). A vida e o ofício do professores: formação contínua e pesquisa em colaboração. São Paulo: Escrituras, 2002.

CARVALHO, José Sérgio F. de. A teoria na prática é outra? Considerações sobre as relações entre teoria e prática em discursos educacionais. Revista Brasileira de Educação, v. 16, n. 47, p. 307-322, maio-ago. 2011.

CHARTIER, Anne-Marie. Práticas de leitura e escrita: história e atualidade. Belo Horizonte: Autêntica, 2007.

CHARTIER, Roger. À beira da falésia: a história entre certezas e inquietude. Porto Alegre: Editora da Universidade/UFRGS, 2002. . A história cultural: entre práticas e representações. Lisboa: Difel, 1990. 
. A história ou a leitura do tempo. Belo Horizonte: Autêntica, 2009.

L'histoire aujourd'hui: doutes, défis, propositions. Texto apresentado em conferência realizada no Instituto de Estudos Avançados - USP, em setembro de 1993.

. 0 mundo como representação. Estudos Avançados, 11 (5), p. 173-191, 1991.

CIAMPI, Helenice.; CABRINI, Conceição.; VIEIRA, Maria do Pilar; PEIXOTO, Maria do Rosário; BORGES, Vavy Pacheco. 0 ensino de história: revisão urgente. 2. ed. São Paulo: Brasiliense, 1986.

CUNHA, Maria Isabel da. 0 bom professor e sua prática. Campinas: Papirus, 1989.

GATTI, Bernadete A.; NUNES, Maria Muniz Rossa. Formação de professores para o ensino fundamental: instituições formadoras e seus currículos. Relatório Final de Pesquisa. 2 vol. São Paulo: Fundação Carlos Chagas, 2008.

GOODSON, Ivor. Currículo: teoria e história. Petrópolis-RJ: Vozes, 1995.

. The making of curriculum. Londres: Falmer Press, 1988.

LYOTARD, Jean-François. A condição pós-moderna. 6. ed. Rio de Janeiro: José Olympio, 1998.

LUCA, Tânia Regina de; BEZERRA, Holien Gonçalves. Em busca da qualidade PNLD História - 1996-2004. In.: SPOSITO, Maria Encarnação Beltrão (org.). Livros didáticos de História e Geografia: avaliação e pesquisa. São Paulo: Cultura Acadêmica, 2006. p. 27-53.

LUCA, Tânia Regina de; MIRANDA, Sonia Regina. 0 livro didático de história hoje: um panorama a partir do PNLD. Revista Brasileira de História, São Paulo, v. 24, n. 48, p. 123144, 2004.

MUNAKATA, Kazumi. 0 livro didático e o professor: entre a ortodoxia e a apropriação. In.: MONTEIRO, Ana Maria; GASPARELLO, Arlette Medeiros; MAGALHÃES, Marcelo de Souza (org.). Ensino de história: sujeitos, saberes e práticas. Rio de Janeiro: Mauad X, 2007. p. 137-148.

NORA, Pierre. Entre memória e história: a problemática dos lugares. Projeto História, São Paulo, n. 10, p. 7-28, dez. 1993.

OLIVEIRA, Margarida Maria Dias de. Livros didáticos de História: pesquisa, ensino e novas utilizações deste objeto cultural. In: ; OLIVEIRA, Almir Felix Batista de (Orgs.). Livros didáticos de História: escolhas e utilizações. Natal: EDUFRN, 2009, p. 79-86.

PAULILO, André Luiz. Os modos de enunciação nos Manuais de Ensino para professores de História. Topoi, v. 11, n. 21, p. 283-302, jul.-dez. 2010.

PIMENTA,Selma Garrido; GHEDIN, Evandro (Org.) Professor reflexivo no Brasil: gênese e critica de um conceito. 3. ed., São Paulo: Cortez, 2005.

SAVIANI, Dermeval. Escola e democracia : teorias da educação, curvatura da vara, onze teses sobre educação e política. 2. ed. São Paulo: Cortez; Autores associados, 1984.

RÜSEN, Jörn. The didactics of history in West Germany: towards a new self-awareness of historical studies. History and theory, Wesleyan University, vol. XXVI, n. 3, 1987. 
What is historical consciousness? A theoretical approach to empirical evidence. British Columbia: CSCH, 2002. In: <http://www.csch.ubc.ca/pwias/viewabstract.php?8>. Acesso em 10 set. 2011.

TARDIF, Maurice. Saberes docentes e formação profissional. 2. ed. Petrópolis, Rio de Janeiro: Vozes. 2002.

ZEICHNER, Kenneth. A formação reflexiva de professores: ideias e práticas. Lisboa: Educa, 1993.

\section{Coleções analisadas no artigo:}

1. Por dentro da História (Pedro Santiago);

2. História em projetos (Andréa Paula, Carla Miucci Ferraresi e Conceição de Oliveira);

3. Projeto Araribá-História (organizado por Editora Moderna);

4. História - das cavernas ao Terceiro Milênio (Myriam Becho Mota e Patrícia Ramos Braick);

5. Diálogos com a História (Kátia Corrêia Peixoto Alves e Regina Célia de Moura Gomide Belisário);

6. Navegando pela História (Maria Luíza Vaz e Sílvia Panazzo);

7. História: conceitos e procedimentos (Eliete Toledo e Ricardo Dreguer);

8. História e vida integrada (Claudino Piletti e Nelson Piletti);

9. História hoje (Oldimar Pontes Cardoso);

10. História em documento: imagem e texto (Joelza Ester Rodrigue);

11. História, sociedade e cidadania (Alfredo Boulos Júnior);

12. Encontros com a história (Carla Maria Junho Anastasia e Vanise Maria Ribeiro);

13. Construindo Consciências: História (Leonel Itaussu de Almeida Mello e Luís César Amad Costa);

14. Saber e fazer História (Gilberto Cotrim);

15. Série Link do tempo: História (Denise Mattos Marino e Léo Stampachio);

16. História por eixos temáticos (Antonio Pedro e Lizânias de Souza Lima);

17. Historiar: fazendo, contando e narrando a História (Dora Schmidt);

18. História temática (Andréa Rodrigues Dias Montelatto, Conceição Aparecida Cabrini e Roberto Catelli Jr.);

19. Descobrindo a História (Sônia Maria Mozer e Vera Lúcia Pereira Telles Nunes). 
Recebida 1a versão em novembro de 2011

Aprovada 2a versão em abril de 2012

André Luiz Paulilo, doutor em Educação pela Universidade de São Paulo. É professor de História da Educação da Faculdade de Educação da Universidade Estadual de Campinas. Publicações recentes: Os manuais do professor das coleções didáticas e os referenciais curriculares como fontes de pesquisa em educação (2011); Os modos de enunciação nos manuais de ensino para professores de história (2010). E-mail: paulilodunicamp.br. 